\title{
Current and recalled symptoms of Attention Deficit Hyperactivity Disorder in parents of children with ADHD
}

\author{
Hemamali Perera, Numega Jayasuriya and Chandima Jeewandara
}

\section{Background}

Attention deficit hyperactivity disorder (ADHD) has a strong genetic aetiology and high heritability. Biological relatives of children with ADHD have a substantial risk of developing this disorder. Accordingly, parents of children with ADHD are likely to have more symptoms of ADHD. Diagnosing ADHD in adults is hampered by lack of agreement on diagnostic criteria.

Aims

To test the hypothesis that parents of children with ADHD have higher prevalence of ADHD symptoms when compared to a control group of parents.

\section{Methods}

Presence of ADHD symptoms in parents were assessed using the Adult ADHD Self-Report Scale (ASRS) to elicit current symptoms and the Wender Utah scale to elicit retrospectively recalled symptoms from childhood. The study group comprised of parents of consecutive attendees of specialist clinics for children with ADHD at a tertiary care institution. Control group was randomly selected from parents of children attending general paediatric clinics. Presence of current ADHD symptoms was assessed using Adult ADHD SelfReport Scale (ASRS). The Wender Utah scale elicited retrospectively recalled symptoms from childhood.

Results

Study group consisted of 117 parents and the control group of 69 parents. Prevalence of ADHD symptoms was higher in the study group, compared to the control group $(21.3 \%$ vs $4.3 \%$ on ASRS and $11.9 \%$ vs $0 \%$ on Wender Utah scale). The odds for having ADHD symptoms in parents of children with ADHD were 5.9, compared to the control group. Correlation of scores on the two scales was high in the study group (0.78) and less in the control group (0.44).

Conclusion

The study shows a high prevalence of symptoms of ADHD in parents of children with ADHD. Further research is indicated to investigate the implication of the findings of this study.

SL J Psychiatry 2011; 2 (1):18-22

\section{Introduction}

Attention deficit hyperactivity disorder (ADHD) is a common behavioural disorder in children, characterised by hyperactivity, attention deficit and impulsiveness that is pervasive to different settings (1). The adult type of the disorder is now recognised though not extensively researched as the childhood type. Diagnosing ADHD in adults has faced many obstacles. Firstly, the presenting features in adult ADHD is somewhat different to that in children and are determined by changes in developmental trends from child to adult $(2,3)$. Hence, childhood diagnostic criteria may not be directly applicable for diagnosis. Reviews of prevalence studies that used DSM IV criteria have questioned their validity (4). Secondly, the age of onset before seven years should be established for fulfilment of the diagnostic criteria. This requires reliable retrospective information, which may not be possible in many cases. Thirdly, meta-analyses on follow-up studies on childhood onset ADHD have shown that the rate of persistence of the full criteria of symptoms for diagnosis of ADHD is low in adults, being about $15 \%$. This is despite the fact that $40 \%$ to $60 \%$ have persistent symptoms until adulthood with a high rate of impairment (5). Fourthly, many adults with ADHD go unrecognised and instead get treated for other disorders that commonly co-occur such as dysthymia, major depression, anxiety disorder, psychoactive substance use disorder and bipolar disorder (6).
This challenge to making a valid diagnosis was overcome in a study that compared the different methods of self-reporting in adults with ADHD, where a good correlation with clinical diagnosis was found (7). This study concluded that patients are the best informants of their symptoms, but noted that under-reporting of the severity of symptoms may occur. At the same time, it has been found that adult patients who were diagnosed with ADHD but did not meet the age criterion due to late onset, had a similar pattern of psychiatric comorbidity, familial transmission and functional impairment when compared to those who fulfilled all criteria for diagnosis including the age of onset before seven years (8). Furthermore, a study investigating the risk of ADHD in children of parents with childhood-onset ADHD found that the rate was significantly higher than that reported for siblings of children with ADHD (9). In addition, the rate of school failure in these parents was almost similar to that reported for children with ADHD. The authors concluded that the results of the study support the validity of an adult diagnosis of ADHD and that the adult form may have stronger familial risk factors than the childhood form.

A strong genetic aetiology has been shown in ADHD in children $(10,11)$. Biological relatives of boys with ADHD are at a higher risk of this disorder and other psychiatric disorders $(12,13,14)$. The familial nature of the disorder in children was also demonstrated in other epidemiological studies and also with individually 
administered psychological tests in children with ADHD and their siblings $(15,16)$. A higher risk of ADHD is also found among girl probands than among relatives of normal girls (17). Heritability of ADHD in adults is estimated to be $30 \%$ in both men and women (18), although substantially lower than that in children, which approximates 75\% (19). An association between ADHD and the DRD4 allele has been found on genotyping involving triads of a parent with ADHD, the spouse and a child with $\operatorname{ADHD}(20,21)$. Among family members, seven repeats of the DRD4 allele predicted the diagnosis of ADHD.

In view of the substantial evidence of genetic risk and familial tendencies with regard to the aetiology of ADHD, we hypothesised that parents of children with ADHD will have a higher rate of ADHD symptoms when compared to a control group of parents. A literature search did not reveal any published studies that have directly investigated this possibility.

\section{Methods}

\section{Participants}

In this descriptive study, parents of children with ADHD who gave voluntary informed consent comprised the study group. They were parents of consecutive clinic attendees over a period of six months. Both parents were contacted as far as possible to avoid sampling bias of selecting only the parent who accompanied the child. All the index children with ADHD were attending a specialist mental health outpatient service and were currently taking stimulant medication. The control group comprised of parents of children attending specialist medical paediatric outpatient clinics, who were randomly selected and gave informed voluntary consent for the study.

\section{Assessment of ADHD symptoms in parents}

The parents reported on ADHD symptoms which were (i) currently present and (ii) retrospectively recalled of their presence in childhood. Two scales were used in the assessment.

1. ADHD symptoms currently present were elicited using the Adult ADHD Self-Report Scale (ASRS-v1.1), which was interviewer-administered. This scale has two parts, $\mathrm{A}$ and $\mathrm{B}$, which carries six and 12 items respectively and are based on DSM IV-TR criteria for ADHD (1). The Items in Part A are more predictive of ADHD and four or more items should be present in sufficient intensity for a diagnosis to be made. A subset of the 18 item ASRS, the six-question WHO Adult Self-Report Scale Screener (22), which includes the six item Part A was used in this study with a cut-off score of 15. Responses were recorded for each item on a five point (0-4) severity scale as never, rarely, sometimes, often and very often.

2. Retrospective recall of ADHD symptoms in childhood was rated using the Wender Utah Rating Scale (23), which was also interviewer administered. This instrument uses a subset of 25 items for retrospective rating of childhood ADHD symptoms on a five point (0-4) severity scale (not at all or very slightly, mildly, moderately, quite a bit and very much). The scale has been useful in identifying adults with
ADHD from those without the disorder and from those with other psychopathology using a cut off score of 46 . It uses Utah criteria for adult ADHD rather than DSM IV criteria, which apply more to children (24).

Both scales were translated into Sinhalese before use and checked for cultural and technical appropriateness of the items. This was done to ensure uniformity in the administration of questions in Sinhalese to the participants. The authors administered the questionnaires to all participants.

Other data gathered included: the age of the parent, highest educational level achieved current employment status change of job since first employment, whether taking alcohol on a regular basis or not (assessment of intensity of alcohol intake was not attempted), whether smoking cigarettes on a regular basis or not (assessment of intensity of smoking was not attempted), history of law breaking behaviour at any time in life leading to encounters with law enforcement authorities but not necessarily resulting in conviction (ranging from criminal behaviour to traffic offences and warnings by police for socially unacceptable conduct), perceived marital problems, past or present (arguments considered by the parent as problematic or assault) and the current marital status.

\section{Statistical analysis}

Statistical analysis was done using SPSS version 16 for Windows. A frequency distribution calculate the prevalence of ADHD symptoms. The Independent $t$ test was used for the comparison of means of scores in the study and control groups.

\section{Results}

A total of 186 parents participated in the study. In the study group, 57 fathers and 60 mothers of children with ADHD (total=117) completed the questionnaires. There were 57 pairs of parents and 3 single mothers in this sample. In the control group, 36 fathers and 33 mothers (total=69) participated. There were 33 pairs of parents and 3 single fathers in this sample. None of the parents had been diagnosed with or was on treatment for a mental disorder. The socio-demographic characteristics are given in table 1 .

\section{Prevalence estimated from ASRS (current symptoms)}

The study group $(n=117)$ had a mean score of 10.9 (range 6-26, $\mathrm{SD}=4.9)$. The control group $(\mathrm{n}=69)$ had a mean score of 9.7 (range $6-19, \mathrm{SD}=3.2$ ). The difference in means was significant (t 2.02; df 181.8; $\mathrm{p}=0.044)$ In the study group, a total of 25 parents $(21.3 \%)$ scored above the cut-off score of 15 . Of these, $20(17.1 \%)$ were fathers and $5(4.3 \%)$ were mothers. The association between gender of parent and ADHD symptoms in the study group (estimated by cross tabulation) was significant $(\mathrm{p}<0.001)$. In the control group, a total of 3 parents $(4.3 \%)$ scored above the cut off score. The overall prevalence of ADHD symptoms in the study group was $21.3 \%$ and that in the control group was $4.3 \%$ (Odds Ratio, OR 5.9). 


\begin{tabular}{|c|c|c|c|c|}
\hline \multirow[t]{2}{*}{ Variables } & \multicolumn{2}{|l|}{ Study Group } & \multicolumn{2}{|l|}{ Control Group } \\
\hline & $\begin{array}{l}\text { Father } \\
\text { frequency (\%) } \\
n=57\end{array}$ & $\begin{array}{l}\text { Mother } \\
\text { frequency (\%) } \\
n=60\end{array}$ & $\begin{array}{l}\text { Father } \\
\text { frequency (\%) } \\
n=36\end{array}$ & $\begin{array}{l}\text { Mother } \\
\text { frequency (\%) } \\
n=33\end{array}$ \\
\hline Age - mean years (SD) & $39(6.9)$ & $34(6.7)$ & $36(6.2)$ & $33(6.3)$ \\
\hline \multicolumn{5}{|l|}{ Level of education } \\
\hline Up to Year 8 & $11(19.3)$ & $12(20.0)$ & $6(16.6)$ & $2(6.0)$ \\
\hline Up to G.C.E.O Level & 29(50.9) & $30(50.0)$ & $21(58.3)$ & $20(60.6)$ \\
\hline Up to G.C.E.A Level & $7(12.3)$ & $10(16.7)$ & $8(22.2)$ & $8(24.2)$ \\
\hline Tertiary education & $6(10.5)$ & $1(1.7)$ & 0 & $3(9.1)$ \\
\hline \multicolumn{5}{|l|}{ Employment } \\
\hline Professional & $6(10.5)$ & $1(1.6)$ & 0 & $1(3.0)$ \\
\hline Skilled worker & $27(47.4)$ & $1(1.6)$ & $21(58.3)$ & $6(18.2)$ \\
\hline Semi-skilled worker & $19(33.3)$ & $7(11.6)$ & $14(38.9)$ & $6(18.2)$ \\
\hline Unskilled worker & $5(8.7)$ & $4(6.6)$ & $1(2.7)$ & $3(9.1)$ \\
\hline Home keeping & 0 & $47(78.3)$ & 0 & $17(51.5)$ \\
\hline \multicolumn{5}{|l|}{ Change of job } \\
\hline None & $31(54.2)$ & NC & $30(83.3)$ & NC \\
\hline 2-4 times & $18(31.6)$ & $8(13.3)$ & $5(13.9)$ & $6(18.2)$ \\
\hline$>5$ times & $8(14.0)$ & 0 & $1(2.8)$ & $1(3.0)$ \\
\hline $\begin{array}{l}\text { Involvement in illegal } \\
\text { activity }\end{array}$ & $9(15.8)$ & $4(4.7 \%)$ & 0 & 0 \\
\hline
\end{tabular}

\section{Prevalence estimated from Wender Utah Scale (retrospectively recalled symptoms)}

The study group $(n=117)$ had a mean score of 19.8 (range $0-86, \mathrm{SD}=1.7)$. The control group $(\mathrm{n}=69)$ had a mean score of 8.9 (range $0-38, \mathrm{SD}=7.7$ ). The difference ine means was significant (t 5.81; df 172.2; $<<.001)$. In the study group, a total of 14 parents $(11.9 \%)$ scored above the cut-off score of 46 . Of these, $11(9.4 \%)$ were fathers and $3(2.6 \%)$ were mothers. Hence, the overall prevalence of ADHD symptoms was $11.9 \%$ in the study group. The association between gender of parent and ADHD symptoms in the study group (estimated by cross tabulation) was significant $(p=0.01)$. On this scale, none scored above the cut off score in the control group.

Pearson's correlation of scores between the ASRS and Wender Utah scales for the study group was 0.78 and significant $(\mathrm{p}=0.001)$. Correlation for the control groups was 0.46 but also significant $(p=0.001$ ). Figure 1 shows comparison of means between ASRS and Wender Utah scores for the study and control groups using the independent $t$ test.

The association between social variables and the presence of ADHD symptoms was calculated only for ASRS scores, as this estimated the current status. The association with regular alcohol intake in fathers in the study group was $\mathrm{p}=0.002(\chi 2=39.28, \mathrm{OR}=1.5)$. Similar figures for the control group were $p=0.003(\chi 2=69.26$, $\mathrm{OR}=0.66)$. Association with regular smoking in fathers in the study group was $p=0.001(\chi 2=42.74, \mathrm{OR}=2.0)$. Similar figures for the control group were $\mathrm{p}=0.004$ $(\chi 2=67.71$, OR $=0.52)$. There was no significant association with law breaking behaviour in the study group $(\chi 2=29.38, p=0.031$,$) . Proportionately more$ fathers in the study group had changed jobs 2-4 times or more when compared to the control group (Table 2). Similarly, proportionately more parents in the study group reported marital problems, when compared to the control group.

\section{Discussion}

The main finding of our study was the high prevalence of ADHD symptoms reported by the parents of children with ADHD when compared to the control group, both in current symptoms $(21.3 \%$ against $4.3 \%)$ and retrospectively recalled symptoms $(11.9 \%$ against $0 \%)$. The odds for having ADHD symptoms in parents of children with ADHD were 5.9, compared to 0.17 in the control group. There are very few prevalence studies in adult ADHD for comparison. In a population screening, the estimated prevalence of adult ADHD was $2.9 \%$ for a narrow definition of ADHD and $16.4 \%$ for a broad definition of ADHD (25). A population point prevalence of $4.4 \%$ was reported in another study (6). This is in keeping with a prevalence of $4.3 \%$ of symptoms of ADHD estimated from the control group. The gender difference in symptoms evident in our results is to be expected in view of ADHD in any age group being more prevalent in males.

Amuch lessernumber of parents reported retrospectively recalled ADHD symptoms from childhood when compared to currently present ADHD symptoms. This discrepancy may have several explanations. Recall bias is one possible reason. Also, missed recognition during childhood, symptoms not being considered relevant in terms of a behavioural problem, and even being considered as normal behaviour for age are 
Table 2- Comparison of study group and control group characteristics

Study group Control group

Substance use

Alcohol use(fathers only) 23(40.3) 0

Cigarette smoking (fathers only 18(31.6) 0

Perceived marital problems

Physical assault $\quad 16(28.1) \quad 0$

$\begin{array}{lll}\text { None identified } 29(50.8) & 26(78.8)\end{array}$

Current marital status

$\begin{array}{lll}\text { Married } & \text { 53(92.9) } 100\end{array}$

Divorced $\quad 1(1.7) \quad 0$

Re-married $\quad 0 \quad 0$

Living separately $3(5.3) \quad 0$

other possible reasons. Conversely, a bias towards over-recognition or over-identification with symptoms of ADHD may lead to higher reporting of current symptoms. Being better informed about the disorder through their contact with child mental health services may contribute to such a situation. Despite this discrepancy, there was a strong correlation $(\mathrm{r}=0.78)$ between the scores from the two assessment tools in parents of children with ADHD. The correlation between the two sets of scores in the control group was weak $(\mathrm{r}=0.44)$ though still statistically significant. Nevertheless, the Wender Utah scale was superior in demonstrating the differences between the study and control groups more than the ASRS (Figure 1), and this difference was statistically significant $(\mathrm{p}<0.001)$. Other studies have also found that the retrospective recall of symptoms is valid in diagnosing adult $\operatorname{ADHD}(26,27$, 28). Conversely, current symptoms from the ASRS better highlighted the difference in the prevalence of

Fig.1 Comparison of means for ASRS and Wender Utah Score between study and control groups

ASRS

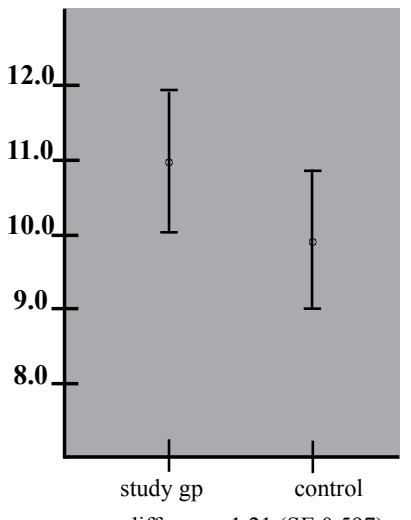

mean difference 1.21 (SE 0.597)
Wender Utah

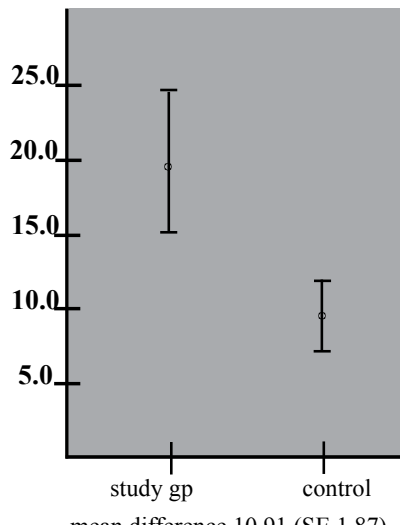

mean difference 10.91 (SE 1.87) symptoms of ADHD between the study and control groups in absolute numbers (21.3\% against $4.3 \%)$, although a statistically significant difference was not evident $(p=0.044)$. However, this was probably due to the low difference between the mean scores.

Although the use of a control group was a particular strength, the assessment tools used in this study being not validated against clinically diagnosed adults is a shortcoming. Hence, the study chose the option of eliciting the presence of symptoms of ADHD (current and retrospectively recalled) rather than make a diagnosis. The higher prevalence of ADHD symptoms among parents of children with ADHD is further strengthened by other findings in the study. For instance, the use of alcohol, smoking and law breaking behaviour was proportionately higher among fathers of children with ADHD when compared to the control group even though a statistical significance was established with symptom scores only with cigarette smoking. Similarly, there were proportionately more unskilled workers among fathers of children with ADHD (10.1\% against 2.9\%). Marital problems were also commoner among fathers of children with ADHD $(25 \%$ against $0 \%)$. Adult ADHD is a well-recognised risk factor for poor employment, low socioeconomic status, marital problems, violence, drug abuse and antisocial behaviour $(6,29,30)$. However, our data was not specific enough to comment on school failure and poor prospects of employment among fathers with symptoms of ADHD.

\section{Conclusion}

The study shows a high prevalence of symptoms of ADHD in parents of children with ADHD. Further investigation into the implications of this finding, especially with regard to the parenting of children with ADHD, is indicated in view of known impairments associated with adults having the disorder.

\section{Declaration of interest}

None

Hemamali Perera, MBBS, MD(Psych), FRCPsych, Professor, Department of Psychological Medicine, Faculty of Medicine, University of Colombo, Sri Lanka Numega Jayasuriya, MBBS,MD (Psych), Senior Registrar in Psychiatry Chandima Jeewandara, MBBS, Medical Officer in Psychiatry Lady Ridgeway Hospital for Children, Colombo, Sri Lanka Corresponding author

Hemamali Perera, Department of Psychological Medicine, Faculty of Medicine, Colombo 08 , Sri Lanka

E mail: hemamali_p@yahoo.com

\section{References}

1. American Psychiatric Association: Diagnostic and Statistical Manual of Mental Disorders, Fourth Edition, Text Revision. American Psychiatric Association. 2000. Washington, DC 
2. Willens TE, Biederman J, Spenser TJ. Attention deficit /hyperactivity disorder across the lifespan. Annu Rev Medicine 2002; 53: 113-131

3. Millstein RB, Wilens TE, Biederman J, Spenser TJ. Presenting ADHD symptoms and subtypes in clinically referred adults with ADHD. J Attention Disorder 1997; $2: 159-166$

4. Simon V, Czobor P, Balint S, Meszaros A, Bitte I. Prevalence and correlated of adult attention-deficit hyperactivity disorder: meta-analysis. Br J Psychiatry 2009; 194: 204-211

5. Faraone SV, Biederman J, Mick E. The age-dependent decline of attention deficit hyperactivity disorder: a meta-analysis of follow-up studies. Psychol Med 2006; 36: $159-165$

6. Kessler RC, Adler L, Barkley R, Biederman J, Conners CK, Demler O, Faraone SV, Greenhill LL, Howes MJ, Secnik K, Spencer T, Ustun TB, Walters EE, Zaslavsky AM: The prevalence and correlates of adult ADHD in the United States: results from the National Comorbidity Survey Replication. Am J Psychiatry 2006; 163:716-723

7. Sandra Kooij JJ, Marije Boonstra A, Swinkels SH, Bekker EM, de Noord I, Buitelaar JK. Reliability, validity and utility of self-report and informant report concerning symptoms of ADHD in adult patients. J Atten Disorder 2008; 11: 445-458

8. Faraone SV, Biederman J, Spencer T, Mick E, Murray K, Adamson JJ, Monuteaux MC. Petty C. Diagnosing adult attention deficit hyperactivity disorder: are late onset and subthreashold diagnoses valid? Am J Psychiatry 2006; 163: 1720-1729.

9. Biederman J, Faraone SV, Mick E, Spence T, Wilens T, Kiely K, Guite J, Ablon JS, Reed E, Warburton R. High risk for attention deficit hyperactivity disorder among children of parents with childhood onset of the disorder: a pilot study. Am J Psychiatry 1995 152: 431-435

10. Faraone SV, Doyle AE The nature and heritability of attention-deficit/ hyperactivity disorder. Child Adolesc Psychiatr Clin N Am 2001; 10: 299-316

11. Franke B, Neale BM, Faraone SV. Genome-wide association studies in ADHD. Hum Genet 2009; 126: 13-50.

12. Faraone S, Biederman J, Chen WJ, Krifcher B, Keenman K, Moore C, Sprich S, Tsuang M. Segregation analysis of attention deficit hyperactivity disorder: evidence for single gene transmission. Psychiatr Genetics 1992; 2: 257-275

13. Faraone S, Biederman J. Is attention deficit hyperactivity disorder familial? Harverd Rev Psychiatry 1994; 1: 271287

14. Faraone SV, Biederman J, Milberger S. An exploratory study of ADHD among second-degree relatives of ADHD children. Biol Psychiatry 1994; 35: 398-402

15. Szatmari P, Boyle MH, Offord DR. Familial aggregation of emotional and behavioral problems of childhood in the general population. Am J Psychiatry 1993; 150: 1398-1403

16. Faraone SV, Biederman J, Krifcher LB, Spencer T, Norman D, Seidman L, Kraus I, Perrin J, Chen W, Tsuang MT. Intellectual performance and school failure in children with attention deficit hyperactivity disorder and in their siblings. J Abnorm Psychology 1993; 102 : 616-623
17. Faraone SV, Biederman J, Keenman K, Tsuang MT. A family-genetic study of girls with DSM III attention deficit disorder. Am J Psychiatry 1991; 148: 112-117

18. Boomsma DI, Saviouk V, Hottenga J-J, Distel MA, de Moor MHM, Vink JM, Geels LM, van Beek JHDA, Bartels M, de Geus EJC, Willemsen G. Genetic epidemiology of attention deficit hyperactivity disorder (ADHD Index) in adults. PLoS ONE / www.plosone.org May 2010; 5: e10621.

19. Biederman J, Faraone SV: Attention-deficit hyperactivity disorder. Lancet 2005; 366:237-248

20. Faraone S, DoyleAE, Mick E, Biederman J. Metaanalysis of association between the 7-repeat allele of dopamine (4) receptor gene and attention deficit hyperactivity disorder. Am J Psychiatry 2001; 158: 1052-7

21. Faraone SV, Biederman J, Weiffenbach B, Keith T, Chu MP, Weaver A, Spencer TJ, Wilens TE, Frazier J, Cleves M, Sakai J. Dopamine D4 gene 7-repeat allele and attention deficit hyperactivity disorder. Am J Psychiatry 1999; 156: 768-70

22. Kessler RC, Adler L, Ames M, Demler O, Faraone S, Hiripi E, Howes MJ, Jin R, Secnik K, Spencer T, Ustun TB, Walters EE: The World Health Organization Adult ADHD Self-Report Scale (ASRS): a short screening scale for use in the general population. Psychol Med 2005; 35: 245-256 http://www.addcoach4u.com/ adultaddtest.html accessed on 8 April 2011

23. Ward MF, Wender PH, Reimherr FW. The Weder Utah Rating Scale: an aid in the retrospective diagnosis of childhood attention deficit hyperactivity disorder. Am J Psychiatry 1993;150: 885-90. http://www.medal.org/ docs_ch18.12.html accessed on

24. Wender PH, Wolf LE, Wasserstein J. Adults with ADHD: an overview. Ann N Y Acad Sci 2001; 931: 1-16

25. Faraone SV, Biederman J. What is the prevalence of adult ADHD? results of a population screen of 966 adults. J Atten Disorder 2005; 9: 384-391

26. Murphy P, Schachar R: Use of self-ratings in the assessment of symptoms of attention deficit hyperactivity disorder in adults. Am J Psychiatry 2000; 157:1156-1159

27. Faraone SV, Biederman J, Feighner JA, Monuteaux MC: Assessing symptoms of attention deficit hyperactivity disorder in children and adults: which is more valid? J Consult Clin Psychol 2000; 68:830-842

28. Faraone SV, Spencer T, Montano CB, Biederman J: Attention deficit hyperactivity disorder in adults: a survey of current practice in psychiatry and primary care. Arch Intern Med 2004; 164:1221-1226

29. McGough JJ, Smalley SL, McCracken JT, Yang M, Del'Homme M, Loo S. Psychiatric comorbidity in adult attention deficit hyperactivity disorder: findings from multiplex families. Am J Psychiatry 2005; 162: 16211627

30. Mannuzza S, Klein RG, Bessler A, Malloy P, LaPadula M: Adult outcome of hyperactive boys: educational achievement, occupational rank, and psychiatric status. Arch Gen Psychiatry 1993; 50:565-576 